\title{
Varenicline improves motor and cognitive symptoms in early Huntington's disease
}

This article was published in the following Dove Press journal:

Neuropsychiatric Disease and Treatment

19 September 2016

Number of times this article has been viewed

\author{
Ailsa L McGregor ${ }^{1,2}$ \\ Jo Dysart ${ }^{3}$ \\ Malcolm D Tingle ${ }^{4}$ \\ Bruce R Russell ${ }^{1,2}$ \\ Rob R Kydd ${ }^{5}$ \\ Gregory Finucane ${ }^{2}$
}

'New Zealand's National School of Pharmacy, Division of Health Sciences, University of Otago, Dunedin, New Zealand; ${ }^{2}$ Centre for Brain Research, University of Auckland, ${ }^{3}$ Liaison Psychiatry, Auckland City Hospital, ${ }^{4}$ Department of Pharmacology and Clinical Pharmacology, ${ }^{5}$ Department of Psychological Medicine, University of Auckland, Auckland, New Zealand

Correspondence: Ailsa L McGregor New Zealand's National School of Pharmacy, Division of Health Sciences, University of Otago, PO Box 56, Dunedin 9054, New Zealand Tel +64 34794235

Email ailsa.mcgregor@otago.ac.nz

\begin{abstract}
The aim of this study was to describe the effects of varenicline, a smoking cessation aid that acts as a nicotinic agonist, on cognitive function in patients with early clinical Huntington's disease (HD) who were current smokers. Three gene-positive patients transitioning to symptomatic HD were evaluated using the Unified Huntington's Disease Rating Scale part I and III (motor and behavioral subscales) at baseline and after 4 weeks of treatment. Cognitive function was assessed using a touch screen computer-based neurocognitive test battery (IntegNeuro ${ }^{\circledR}$ ). Varenicline (1 mg twice daily) significantly improved performance in executive function and emotional recognition tasks. Our case reports describe no clinically significant adverse effects and suggest that varenicline improves aspects of cognitive function in patients with early HD. A randomized controlled study is now underway.
\end{abstract}

Keywords: varenicline, Huntington's disease, cognitive symptoms

\section{Introduction}

Huntington's disease (HD) is a fatal, inherited neurodegenerative disorder characterized by progressive movement characterized by progressive motor, cognitive, and psychiatric symptoms. While clinical diagnosis typically depends on motor abnormalities, predictive genetic testing of patients with HD has shown that very early changes in cognitive function occur in gene carriers before any other clinical symptoms are apparent. ${ }^{1,2}$ Cognitive dysfunction includes impairments in executive function, perception, visuospatial and psychomotor skills, memory loss, and problems learning new skills. These cognitive deficits ultimately lead to frontal and subcortical dementia. ${ }^{3,4}$

Patients with HD also have a significant lifetime prevalence of psychiatric disorders. ${ }^{5}$ Frequently reported psychiatric symptoms include depression, anxiety, irritability, apathy, obsessions and compulsions, and psychoses. ${ }^{6}$ For many patients and their families, neuropsychiatric symptoms constitute the most distressing aspect of HD. Combined with the progressive decline in cognitive function, these behavioral symptoms have a significant impact on disease coping, interpersonal relationships, judgment, and the ability to live independently. ${ }^{7}$

The cognitive deficits associated with normal aging and age-related neurodegenerative diseases are proposed to be caused by impairments in cholinergic neurotransmission, in part due to a reduction in the number of nicotinic acetylcholine receptors (nAChRs). ${ }^{8,9}$ However, postmortem analysis of the HD brain shows no change in the number of nAChRs, rather a significant loss of the neurotransmitter acetylcholine, its key synthetic enzyme (choline acetyl transferase), and transporter (vesicular acetylcholine transporter). ${ }^{10-13}$ These neurochemical changes within the brain correlate with cognitive defects ${ }^{3}$ and support the hypothesis that dysfunctional 
cholinergic transmission, through a loss of agonist, rather than receptors, may be a significant contributing factor in the cognitive decline observed in HD.

This presents an opportunity to investigate whether pharmacological replacement with an exogenous agonist can improve cognitive function in HD. Indeed, small-scale clinical studies investigating the procholinergic effects of rivastigmine and donepezil in patients with HD indicated a trend for improved cognitive performance. ${ }^{14-16}$ Further, the nicotine analog varenicline $\left(\right.$ Champix $\left.^{\circledR}\right)$ used for smoking cessation $^{17,18}$ has been shown to improve symptoms in rodent models and in patients with ataxic neurodegenerative disorders ${ }^{19-21}$ and to display antidepressant activity. ${ }^{22}$

While recent evidence suggests no increased risk of neuropsychiatric events, ${ }^{23}$ we performed an open-label study to determine the tolerability of varenicline, a high-affinity agonist at $\alpha 7$ and partial agonist at $\alpha 4 \beta 2 \mathrm{nAChR}$ subtypes, ${ }^{24,25}$ and its effects on cognitive function in three patients with early HD who smoked.

\section{Case reports}

\section{Clinical assessment}

Varenicline (Champix ${ }^{\circledR}$ ) was administered according to the standard regimen for smoking cessation (initiated at $0.5 \mathrm{mg} / \mathrm{d}$ and escalated over a 2 -week period to $2 \mathrm{mg} / \mathrm{d}$ ). The frequency, intensity, and burden of side effects were recorded weekly, in addition to self-reported cigarette use. Disease symptom severity was assessed at baseline and after 4-week treatment with varenicline using parts I (motor) and III (behavior) of the Unified Huntington's Disease Rating Scale (UHDRS). Categories within part I were analyzed separately: ${ }^{26}$ oculomotor function (ocular pursuit, saccade initiation, saccade velocity), hyperkinesia (chorea, dystonia, tongue protrusion, dysarthria), fine motor tasks (finger taps, hand pronation/ supination, Luria), Parkinsonism (rigidity, bradykinesia), and gait (gait, tandem walking, retropulsion). Categories in part III were analyzed in component parts (depressed mood, apathy, low self-esteem/guilt, suicidal thoughts, anxiety, irritable behavior, aggressive behavior, obsessional thinking, compulsive behavior, delusion, and hallucinations). Higher scores for both UHDRS subscales reflect greater impairment.

Cognitive function was assessed using the fully validated IntegNeuro ${ }^{\mathrm{TM}}$ computerized neurocognitive test battery (Brain Resource Company Ltd). The computerized tests show a significant degree of overlap with traditional paper and pencil tests examining the same cognitive construct. ${ }^{27}$ Domains assessed were manual dexterity (motor tapping), impulsivity and attention (Go-No-Go), switching attention, verbal interference, executive maze, and basic emotion recognition, in addition to a measure of premorbid intelligence (spot the real word). IntegNeuro uses different task versions for repeat testing sessions to minimize the effect of familiarization and practice effects, and test-retest reliability measures have shown a high level of consistency (on average 0.70 ). ${ }^{28}$ Raw data from the neuropsychological tests were converted to $z$-scores normalized for age, sex, and years of education based on a database of $>5,000$ control subjects provided by the Brain Resource Company. ${ }^{29}$ All $z$-scores were computed so that positive scores indicated better performance. Subjects were considered to show a significant deficit in a test if the $z$-score for any performance measure of that test was beyond two standard deviations below the mean of the age, sex, and education-matched controls in the Brain Resource Company database. Performance measure scores within each test were averaged to produce a domain-specific $z$-score for each participant. ${ }^{30}$ Formal statistical analysis to determine group differences in domain-specific $z$-scores pre and post treatment was not performed due to the small number of cases.

Baseline assessment and follow-up (after 4 weeks of treatment) were carried out by the same clinicians (GF and JD) and are reported in Tables 1 and 2 . The study design was reviewed and approved by the Southern X Regional Ethics Committee (Health and Disability Ethics Committee, New Zealand). Written informed consent was obtained from all participants after the study had been fully explained. All patients were deemed by their treating physician as having capacity to give informed consent.

\section{Case I}

A 45-year-old female patient (smoked 15 cigarettes/d) was diagnosed with HD in 2013. Neurological examination showed subtle chorea and dystonic posturing of the arms but no other motor features. Baseline cognitive testing demonstrated significant deficits in motor tapping (number of taps, nondominant), maze navigation (number of trials completed, overrun errors), and emotional identification (accuracy of fear

Table I UHDRS part I (motor) scores at baseline and 4 weeks after varenicline treatment

\begin{tabular}{llllll}
\hline Patient & \multicolumn{2}{l}{ Case I } & & & \multicolumn{2}{l}{ Case 2 } \\
\cline { 2 - 3 } \cline { 5 - 6 } \cline { 5 - 6 } & Baseline & 4 weeks & & Baseline & 4 weeks \\
\hline Oculomotor function & 2 & 0 & & 0 \\
Hyperkinesia & 6 & 3 & & 4 & 5 \\
Fine motor tasks & 5 & 4 & & 4 & 3 \\
Parkinsonism & $\mathrm{I}$ & 0 & & 2 & 0 \\
Gait & 2 & 2 & & I & 0 \\
Total motor score & 16 & 9 & & II & 8
\end{tabular}

Abbreviation: UHDRS, Unified Huntington's Disease Rating Scale. 
Table 2 UHDRS part III (behavior) scores at baseline and 4 weeks after varenicline treatment

\begin{tabular}{|c|c|c|c|c|}
\hline \multirow[t]{2}{*}{ Patient } & \multicolumn{2}{|l|}{ Case I } & \multicolumn{2}{|l|}{ Case 2} \\
\hline & Baseline & 4 weeks & Baseline & 4 weeks \\
\hline Depressed mood & 0 & 0 & 0 & 0 \\
\hline Apathy & 0 & 0 & 0 & 2 \\
\hline Low self-esteem & 0 & 0 & 0 & 0 \\
\hline Suicidal thoughts & 0 & 0 & 0 & 0 \\
\hline Anxiety & 0 & 0 & 0 & 0 \\
\hline Irritability & 2 & 3 & $\mathrm{I}$ & $\mathrm{I}$ \\
\hline Aggression & 0 & 5 & 0 & 5 \\
\hline Obsessive thinking & 0 & 0 & 0 & 0 \\
\hline Compulsions & 0 & 0 & 3 & 0 \\
\hline Delusions & 0 & 0 & 0 & 0 \\
\hline Hallucinations & 0 & 0 & 0 & 0 \\
\hline Total behavior score & 2 & 8 & 4 & 8 \\
\hline
\end{tabular}

Abbreviation: UHDRS, Unified Huntington's Disease Rating Scale.

and disgust recognition) compared to age, sex, and years of education-matched controls. No deficits were observed in any of the other cognitive domains tested.

At the time of the study, she was on no medication but had taken venlafaxine to manage depression in the past. She indicated a desire to stop smoking and had previous failed attempts. The patient successfully stopped smoking during week 2 . The patient reported a single aggressive outburst that was out of character during week 2 but experienced no other side effects. After 4 weeks of varenicline treatment, UHDRS total motor score decreased from 16 to 9 with notable improvement in oculomotor function and hyperkinesia scores (Table 1). Her UHDRS behavioral subscale score was increased from 2 to 8 and could be attributed to the episode of increased irritability/aggression (Table 2). The patient self-reported an improvement in her thinking, being able to think more clearly and having a better memory. Cognitive testing showed significant improvements in maze navigation (domainspecific $z$-score: -3.25 vs -0.15$)$ and facial emotion recognition (domain-specific $z$-score: -3.10 vs -1.50 ) following varenicline treatment (Figure 1). Motor-tapping deficits were not affected by varenicline treatment. She continues to be a nonsmoker and has had no further irritable outbursts.

\section{Case 2}

A 44-year-old male patient, diagnosed with HD in 2014, showed slight slowing of rapid alternating movements in the upper limbs and mildly slowed finger tapping on the left side on neurological examination. Chorea and behavioral symptoms were treated with haloperidol $(0.5 \mathrm{mg} / \mathrm{d})$, quetiapine $(200 \mathrm{mg} / \mathrm{d})$, and citalopram $(30 \mathrm{mg} / \mathrm{d})$ at the time of the study. The patient displayed significant deficits in switching of attention (completion time), verbal interference (congruent accuracy, congruent and incongruent reaction time), maze navigation (trials completed, overrun errors, total errors), and emotional identification (accuracy of fear, disgust, and happiness identification) tasks at the baseline clinic visit. He had no desire to stop smoking and continued to smoke $\sim 23$ cigarettes/d throughout the study. He self-reported that there had been an incident where he became extremely agitated and kicked the door in week 2 ; however, this passed quickly and he was unable to recall the cause. No other side effects were reported. Following 4 weeks of varenicline treatment, UHDRS total motor score decreased from 11 to 8 . While fine motor task and gait scores showed modest improvement, hyperkinesia and Parkinsonism scores were moderately elevated (Table 1). His UHDRS behavioral subscale increased from 4 to 8 , due to the aggressive outburst (Table 2). Cognitive testing at 4 weeks showed significantly improved performance in the switching attention (domain $z$-score: $-4.00 \mathrm{vs}-1.7$ ) and verbal interference (domain $z$-score: -2.95 vs -1.90 ) tasks. Performance in tests of executive function (domain $z$-score: -2.82 vs -1.72 ) and emotional identification (domain $z$-score: -2.13 vs -1.03 ) was also significantly improved (Figure 1). He continues to smoke and has reported no further episodes of aggression or irritability.
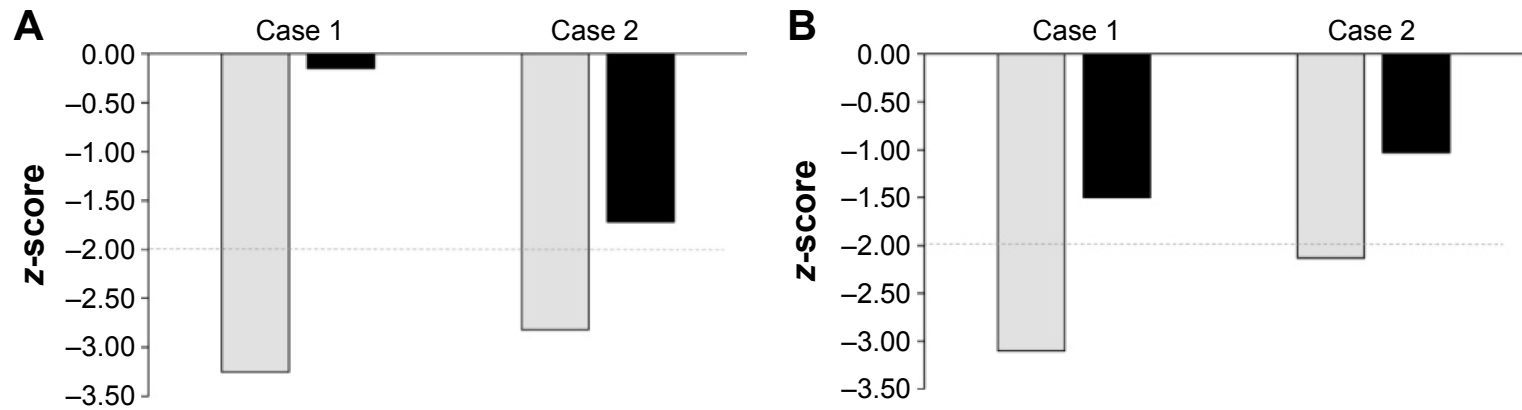

$\square$ Baseline $\square$ weeks

Figure I Cognitive domain scores relative to healthy controls at baseline and 4 weeks for $(\mathbf{A})$ executive function (maze navigation) and (B) emotional identification. 


\section{Case 3}

The patient was a 40-year-old gene-positive male who had required support to manage behavioral symptoms since 2011. Baseline neurological examination showed no motor symptoms (UHDRS total motor score 0 ) and a behavioral subscale score of 14 . He enjoyed smoking ( 20 cigarettes/d) and had no plan to give up. At the time of the study, he was on no medication and reported no effects or side effects of the medication at lower doses $(0.5 \mathrm{mg} / \mathrm{d}$ and $1.0 \mathrm{mg} / \mathrm{d})$. When the daily dosage of varenicline was increased $(2 \mathrm{mg} / \mathrm{d})$, he reported significant alterations in his sense of taste and was unable to drink coffee or take any dairy products. As a result, he discontinued the medication and did not attend follow-up appointments. He was reviewed in the community several months later, and both he and his mother reported that no other side effects were noted other than altered taste.

\section{Discussion}

To our knowledge, this is the first report describing beneficial effects of the nicotinic agonist varenicline on motor and cognitive symptoms in patients with early HD. Our preliminary investigation indicates that varenicline was generally well tolerated in these patents, and no clinically significant adverse effects were reported during the 4-week treatment period. Two patients (cases 1 and 2) reported single, brief episodes of increased irritability and aggression in the second week of varenicline treatment, which may be related to dose escalation from $1 \mathrm{mg} / \mathrm{d}$ to $2 \mathrm{mg} / \mathrm{d}$. The third patient (case 3) did not continue treatment beyond week 2 , due to changes in taste.

No studies have directly investigated smoking in HD; however, previous literature suggests that a significant proportion of patients with HD (40\%) are moderate or heavy smokers. ${ }^{31}$ In the first patient we treated, varenicline was an effective smoking cessation aid. The contribution of nicotine withdrawal to the observed increase in irritability in this patient remains unclear.

Approximately $40 \%$ of smokers achieve abstinence with varenicline, ${ }^{32,33}$ and end-of-treatment abstinence rates increase with increasing varenicline exposure. ${ }^{34}$ Our result of abstinence in one of three patients after a 4-week treatment is in keeping with these observations. Both patients who completed the study were fully adherent; therefore, smoking cessation efficacy may be related to intention to quit or lower baseline smoking status. ${ }^{34}$

The patients who completed the course of treatment showed modest motor symptoms assessed by UHDRS but no clinically significant anxiety or depression (assessed by the hospital anxiety and depression rating scale) ${ }^{35}$ at the time of the study. While both patients displayed different profiles with regard to which specific aspects of attention and verbal tasks were impaired at baseline, both showed impairments of comparable magnitude in maze navigation and emotional identification tasks. This is in agreement with previous literature describing early impairments in executive function, perception, and visuospatial and psychomotor skills. ${ }^{3,4}$

Following 4 weeks of treatment with varenicline, both patients showed significantly improved performance in maze navigation and improved accuracy of fear and disgust recognition. Deficits in emotion recognition, in particular negative emotions, are a key predictor of clinical diagnosis and progression of HD. ${ }^{36-38}$ Reversal of this disease biomarker after a relatively brief period of administration suggests that varenicline may have effects that justify further investigation. The cognitive assessment battery used in this study displays equivalent levels of test-retest reliability over a 4-week period to the MATRICS cognitive consensus battery, and these improvements are unlikely to be due to practice effects. ${ }^{39}$

Cholinergic neurotransmission is an important modulator of cognition within the central nervous system. Indeed, disrupted cholinergic neurotransmission is associated with deficits in emotional processing ${ }^{40}$ and executive function. ${ }^{41,42}$ We hypothesized that impaired cholinergic neurotransmission through a loss of agonist, rather than nAChRs, may contribute to the cognitive decline in patients with HD. Stimulation of nAChRs with nicotine has been shown to improve working memory, visual memory, informationprocessing speed, and emotion recognition in subjects with low baseline cognitive function. ${ }^{43}$ Therefore, it is likely that the cognitive enhancing effects of varenicline are mediated through its effects as a full agonist at $\alpha 7$ and partial agonist at $\alpha 4 \beta 2 \mathrm{nAChRs}$, the subtypes thought to be most important in cognitive function..$^{44,45}$

Varenicline has been previously reported to improve balance and coordination and attenuate ataxias induced by L-Dopa via $\alpha 4 \beta 2$ nAChRs. ${ }^{46}$ Partial agonist effects at this subtype may underlie the improvements in motor function observed in this study. It remains unclear whether a larger effect size would have been observed following a longer treatment period with varenicline or whether varenicline has the potential to improve motor deficits in late-stage patients.

\section{Conclusion}

Our case reports suggest that varenicline may provide multiple benefits by reducing the negative health impact of tobacco 
smoking, in addition to providing beneficial effects on motor and cognitive symptoms. A randomized control trial is now underway to further investigate the efficacy of varenicline in the symptomatic treatment of patients with HD.

\section{Acknowledgment}

This work was supported by the Health Research Council New Zealand (grant number 3620187) and the New Zealand Pharmacy Education Research Trust (grant number 264).

\section{Disclosure}

The authors have no commercial relationships and declare no conflicts of interest in this work.

\section{References}

1. Phillips W, Shannon KM, Barker RA. The current clinical management of Huntington's disease. Mov Disord. 2008;23(11):1491-1504.

2. You SC, Geschwind MD, Sha SJ, et al. Executive functions in premanifest Huntington's disease. Mov Disord. 2014;29(3):405-409.

3. Montoya A, Price BH, Menear M, Lepage M. Brain imaging and cognitive dysfunctions in Huntington's disease. J Psychiatry Neurosci. 2006;31(1):21-29.

4. Novak MJ, Tabrizi SJ. Huntington's disease: clinical presentation and treatment. Int Rev Neurobiol. 2011;98:297-323.

5. van Duijn E, Kingma EM, Timman R, et al. Cross-sectional study on prevalences of psychiatric disorders in mutation carriers of Huntington's disease compared with mutation-negative first-degree relatives. $J$ Clin Psychiatry. 2008;69(11):1804-1810.

6. van Duijn E, Kingma EM, van der Mast RC. Psychopathology in verified Huntington's disease gene carriers. J Neuropsychiatry Clin Neurosci. 2007;19(4):441-448.

7. Van Liew C, Gluhm S, Goldstein J, Cronan TA, Corey-Bloom J. The functional implications of motor, cognitive, psychiatric, and social problem-solving states in Huntington's disease. Psychiatry. 2013;76(4): 323-335.

8. Zanardi A, Leo G, Biagini G, Zoli M. Nicotine and neurodegeneration in ageing. Toxicol Lett. 2002;127(1-3):207-215.

9. Perry EK, Perry RH, Smith CJ, et al. Nicotinic receptor abnormalities in Alzheimer's and Parkinson's diseases. J Neurol Neurosurg Psychiatry. 1987;50(6):806-809.

10. Bates G, Tabrizi S, Jones L, editors. Huntington's Disease. 4th ed. Oxford University Press, Oxford, UK; 2014.

11. Waldvogel HJ, Kim EH, Tippett LJ, Vonsattel JP, Faull RL. The neuropathology of Huntington's disease. Curr Top Behav Neurosci. 2015; 22:33-80.

12. Spokes EG. Neurochemical alterations in Huntington's chorea: a study of post-mortem brain tissue. Brain. 1980;103(1):179-210.

13. Lange KW, Javoy-Agid F, Agid Y, Jenner P, Marsden CD. Brain muscarinic cholinergic receptors in Huntington's disease. J Neurol. 1992; 239(2):103-104

14. Fernandez HH, Friedman JH, Grace J, Beason-Hazen S. Donepezil for Huntington's disease. Mov Disord. 2000;15(1):173-176.

15. Rot U, Kobal J, Sever A, Pirtosek Z, Mesec A. Rivastigmine in the treatment of Huntington's disease. Eur J Neurol. 2002;9(6):689-690.

16. de Tommaso M, Specchio N, Sciruicchio V, Difruscolo O, Specchio LM. Effects of rivastigmine on motor and cognitive impairment in Huntington's disease. Mov Disord. 2004;19(12):1516-1518.

17. Coe JW, Brooks PR, Vetelino MG, et al. Varenicline: an alpha4beta2 nicotinic receptor partial agonist for smoking cessation. J Med Chem. 2005;48(10):3474-3477.

18. Tonstad S, Rollema H. Varenicline in smoking cessation. Expert Rev Respir Med. 2010;4(3):291-299.
19. Zesiewicz TA, Sullivan KL. Treatment of ataxia and imbalance with varenicline (chantix): report of 2 patients with spinocerebellar ataxia (types 3 and 14). Clin Neuropharmacol. 2008;31(6):363-365.

20. Zesiewicz TA, Sullivan KL, Gooch CL, Lynch DR. Subjective improvement in proprioception in 2 patients with atypical Friedreich ataxia treated with varenicline (Chantix). J Clin Neuromuscul Dis. 2009; 10(4):191-193.

21. Zesiewicz TA, Greenstein PE, Sullivan KL, et al. A randomized trial of varenicline (Chantix) for the treatment of spinocerebellar ataxia type 3. Neurology. 2012;78(8):545-550.

22. Rollema H, Guanowsky V, Mineur YS, et al. Varenicline has antidepressant-like activity in the forced swim test and augments sertraline's effect. Eur J Pharmacol. 2009;605(1-3):114-116.

23. Thomas KH, Martin RM, Knipe DW, Higgins JP, Gunnell D. Risk of neuropsychiatric adverse events associated with varenicline: systematic review and meta-analysis. BMJ. 2015;350:h1109.

24. Obach RS, Reed-Hagen AE, Krueger SS, et al. Metabolism and disposition of varenicline, a selective alpha4beta2 acetylcholine receptor partial agonist, in vivo and in vitro. Drug Metab Dispos. 2006;34(1):121-130.

25. Mihalak KB, Carroll FI, Luetje CW. Varenicline is a partial agonist at alpha4beta2 and a full agonist at alpha7 neuronal nicotinic receptors. Mol Pharmacol. 2006;70(3):801-805.

26. Ciammola A, Sassone J, Colciago C, et al. Aripiprazole in the treatment of Huntington's disease: a case series. Neuropsychiatr Dis Treat. 2009;5:1-4.

27. Paul RH, Lawrence J, Williams LM, Richard CC, Cooper N, Gordon E. Preliminary validity of "integneuro": a new computerized battery of neurocognitive tests. Int J Neurosci. 2005;115(11):1549-1567.

28. Williams LM, Simms E, Clark CR, Paul RH, Rowe D, Gordon E. The test-retest reliability of a standardized neurocognitive and neurophysiological test battery: "neuromarker". Int J Neurosci. 2005;115(12): 1605-1630.

29. Clark CR, Paul RH, Williams LM, et al. Standardized assessment of cognitive functioning during development and aging using an automated touchscreen battery. Arch Clin Neuropsychol. 2006;21(5):449-467.

30. Anderson DJ, Malysz J, Gronlien JH, et al. Stimulation of dopamine release by nicotinic acetylcholine receptor ligands in rat brain slices correlates with the profile of high, but not low, sensitivity alpha4beta2 subunit combination. Biochem Pharmacol. 2009;78(7):844-851.

31. Ehret JC, Day PS, Wiegand R, Wojcieszek J, Chambers RA. Huntington disease as a dual diagnosis disorder: data from the national research roster for Huntington disease patients and families. Drug Alcohol Depend. 2007;86(2-3):283-286.

32. Brose LS, West R, Stapleton JA. Comparison of the effectiveness of varenicline and combination nicotine replacement therapy for smoking cessation in clinical practice. Mayo Clin Proc. 2013;88(3): 226-233.

33. Ebbert JO, Wyatt KD, Hays JT, Klee EW, Hurt RD. Varenicline for smoking cessation: efficacy, safety, and treatment recommendations. Patient Prefer Adherence. 2010;4:355-362.

34. Ravva P, Gastonguay MR, Faessel HM, LeeTC, Niaura R. Pharmacokineticpharmacodynamic modeling of the effect of varenicline on nicotine craving in adult smokers. Nicotine Tob Res. 2015;17(1):106-113.

35. Zigmond AS, Snaith RP. The hospital anxiety and depression scale. Acta Psychiatr Scand. 1983;67(6):361-370.

36. Bora E, Velakoulis D, Walterfang M. Social cognition in Huntington's disease: a meta-analysis. Behav Brain Res. 2016;297:131-140.

37. Loffler LA, Radke S, Morawetz C, Derntl B. Emotional dysfunctions in neurodegenerative diseases. J Comp Neurol. 2016;524(8):1727-1743.

38. Baez S, Herrera E, Gershanik O, et al. Impairments in negative emotion recognition and empathy for pain in Huntington's disease families. Neuropsychologia. 2015;68:158-167.

39. Silverstein SM, Jaeger J, Donovan-Lepore AM, et al. A comparative study of the MATRICS and IntegNeuro cognitive assessment batteries. J Clin Exp Neuropsychol. 2010;32(9):937-952.

40. Mason SL, Zhang J, Begeti F, et al. The role of the amygdala during emotional processing in Huntington's disease: from pre-manifest to late stage disease. Neuropsychologia. 2015;70:80-89. 
41. Wallace TL, Bertrand D. Importance of the nicotinic acetylcholine receptor system in the prefrontal cortex. Biochem Pharmacol. 2013; 85(12):1713-1720.

42. Logue SF, Gould TJ. The neural and genetic basis of executive function: attention, cognitive flexibility, and response inhibition. Pharmacol Biochem Behav. 2014;123:45-54.

43. Niemegeers P, Dumont GJ, Quisenaerts C, et al. The effects of nicotine on cognition are dependent on baseline performance. Eur Neuropsychopharmacol. 2014;24(7):1015-1023.
44. Levin ED, Bradley A, Addy N, Sigurani N. Hippocampal alpha 7 and alpha 4 beta 2 nicotinic receptors and working memory. Neuroscience. 2002;109(4):757-765.

45. Levin ED. alpha7-Nicotinic receptors and cognition. Curr Drug Targets. 2012;13(5):602-606.

46. Quik M, Zhang D, Perez XA, Bordia T. Role for the nicotinic cholinergic system in movement disorders; therapeutic implications. Pharmacol Ther. 2014;144(1):50-59.

\section{Publish your work in this journal}

Neuropsychiatric Disease and Treatment is an international, peerreviewed journal of clinical therapeutics and pharmacology focusing on concise rapid reporting of clinical or pre-clinical studies on a range of neuropsychiatric and neurological disorders. This journal is indexed on PubMed Central, the 'PsycINFO' database and CAS, and is the official journal of The International Neuropsychiatric Association (INA). The manuscript management system is completely online and includes a very quick and fair peer-review system, which is all easy to use. Visit http://www.dovepress.com/testimonials.php to read real quotes from published authors.

Submit your manuscript here: http://www.dovepress.com/neuropsychiatric-disease-and-treatment-journal 